\title{
Theoretical Study of Catalytic Dinitrogen Reduction under Mild Conditions
}

\author{
Markus Reiher ${ }^{\dagger 1}$, Boris Le Guennic ${ }^{\dagger, \ddagger}$ and Barbara Kirchner ${ }^{\ddagger}$ \\ ${ }^{\dagger}$ Institut für Physikalische Chemie, Universität Jena, Helmholtzweg 4, \\ D-07743 Jena, Germany \\ ‡ Lehrstuhl für Theoretische Chemie, Universität Bonn, Wegelerstraße 12, \\ D-53115 Bonn, Germany
}

\section{SUPPLEMENTARY MATERIAL}

Date: November 09, 2005

Status: submitted to Inorg. Chem.

\footnotetext{
${ }^{1}$ Correspondence to: M. Reiher (markus.reiher@uni-jena.de
} 


\section{Quantum Chemical Methodology}

For all calculations we used the density functional programs provided by the Turbomole 5.1 and 5.6 suites [1] and employed the Becke-Perdew functional dubbed BP86 [2,3]. The structures were fully optimized until the length of the gradient vector had approached a value of about 0.001 and the energetical difference of the last twenty structures in the optimization process was below $1 \mathrm{~kJ} / \mathrm{mol}$. Note that the deviation of BP86 bond lengths (most likely due to the approximations in the functional) can become as large as $4 \mathrm{pm}$ when compared to the X-ray structures. We tested various arrangements of the sterically demanding chelate ligand in order to guarantee that an optimum conformation was found. All further structures were optimized starting from this pre-optimized arrangement. For the Mo atom, effective core potentials of the Stuttgart group were applied [4], which also take into account scalar relativistic effects. In connection with the BP86 functional we always applied the resolution of the identity (RI) density fitting technique [5,6] for the sake of efficiency. We used Ahlrichs' TZVP basis set [7] featuring a valence triple-zeta basis with polarization functions for all nitrogen and molybdenum atoms. For carbon and hydrogen atoms we employed the smaller split-valence SVP basis set with polarization functions on both types of atoms [8]. We would like to emphasize that the complexes under consideration comprise about 280 atoms which were all treated explicitly (except for the core of the Mo central ion, which was replaced by the ECP). However, a correction for the basis set superposition error (BSSE) has not been taken into account. The BSSE for the TZVP basis set with respect to coordination energies is about $10 \mathrm{~kJ} / \mathrm{mol}$ (see, for instance, Ref. [9]) and therefore it is negligible for the discussion of coordination energies of $\mathrm{N}_{2}$ or $\mathrm{NH}_{3}$.

Test calculations on smaller model complexes showed that B3LYP [10,11] and BP86/RI yield comparable reaction energetics [12]. All energies are given for the low-spin species and are not corrected for zero-point vibrational energy and temperature effects, which can be considered to be small. The potential role of spin states of higher multiplicity had been noticed by Studt and Tuczek [13] and was confirmed in our recent comparison [12]. 


\section{Additional results not incorporated in the main text of the communication}

Many intermediates of Schrock's catalytic cycle (Fig. 1) were isolated and a wealth of experimental data was provided. However, insight into the energetics of the molecular processes is still lacking, which is the starting point for this work.

Figure 1: Schrock's catalytic cycle $[14,15]$. The small letters label reaction steps discussed in the text.

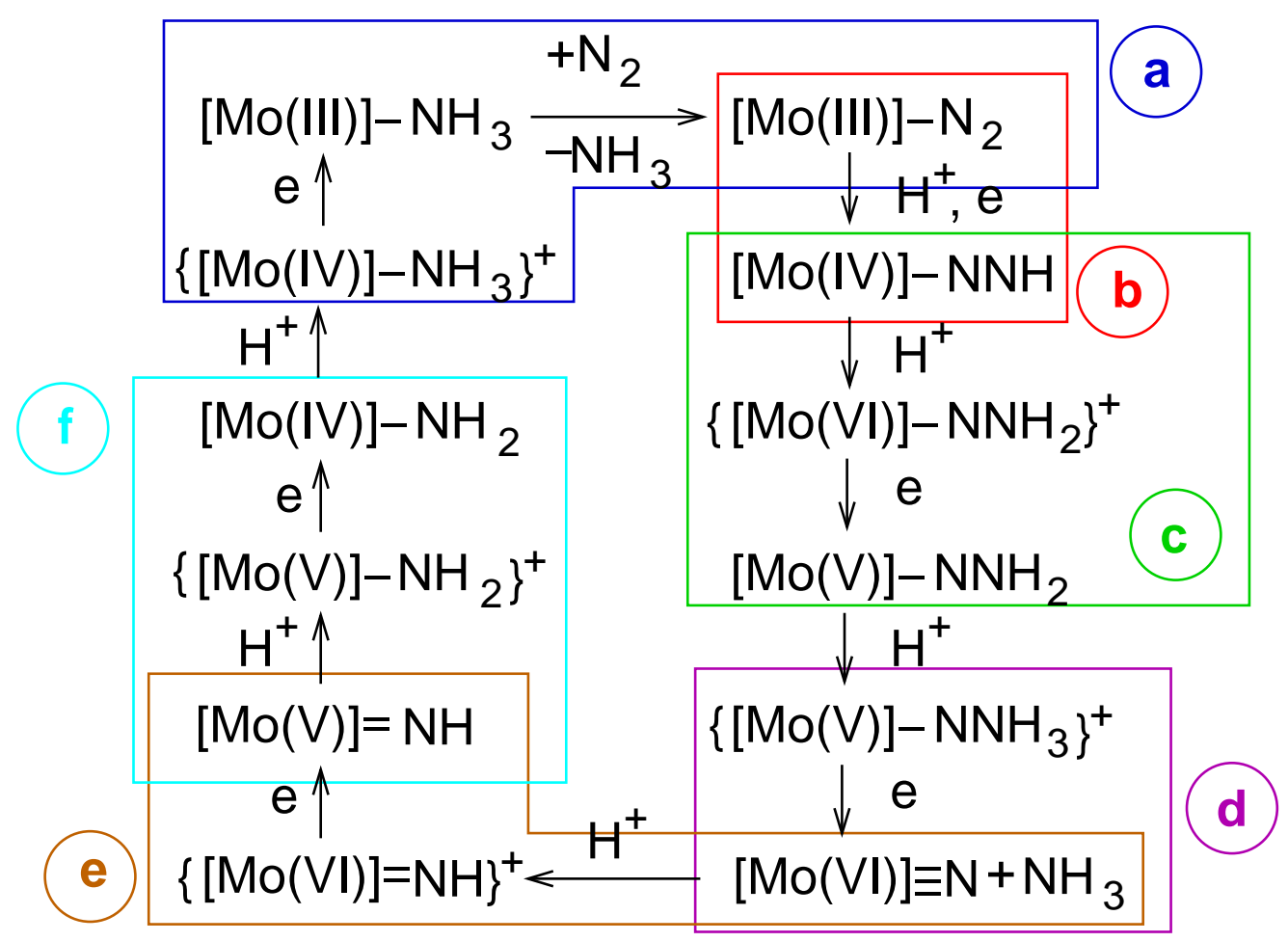

The main aim of this density functional theory (DFT) study is to uncover the thermodynamic boundary conditions for dinitrogen reduction under mild and ambient conditions. Schrock et al. note that the catalytic reaction is extremely finely balanced [16] and that relatively subtle steric and electronic variations of the $\left[\mathrm{TerN}_{3} \mathrm{~N}\right]^{3-}$ ligand produce profound changes in the efficacy of the catalytic reduction of dinitrogen to ammonia [17]. For these reasons we shall not simplify the triamidoamine chelate ligand of the complex but analyze the molybdenum 
complex with the full $\left[(\mathrm{HIPT}-\mathrm{N})_{3} \mathrm{~N}\right]^{3-}$ chelate ligand (compare Fig. (2)) for representative structures and Table 1 for the optimized $\mathrm{N} \equiv \mathrm{N}$ bond lengths of the $[\mathrm{Mo}] \mathrm{N}_{2}^{ \pm, 0}$ complexes).

Figure 2: Optimized structures of $\mathrm{N}_{2}$ and $\mathrm{NNH}_{3}^{+}$coordinated to the triamidoamine metal fragment. Three characteristic bond lengths, $\mathrm{N}_{\beta}-\mathrm{N}_{\alpha}, \mathrm{N}_{\alpha}-\mathrm{Mo}$, and $\mathrm{Mo}-\mathrm{N}_{a m}$, resp., are given in $\mathrm{pm}$.

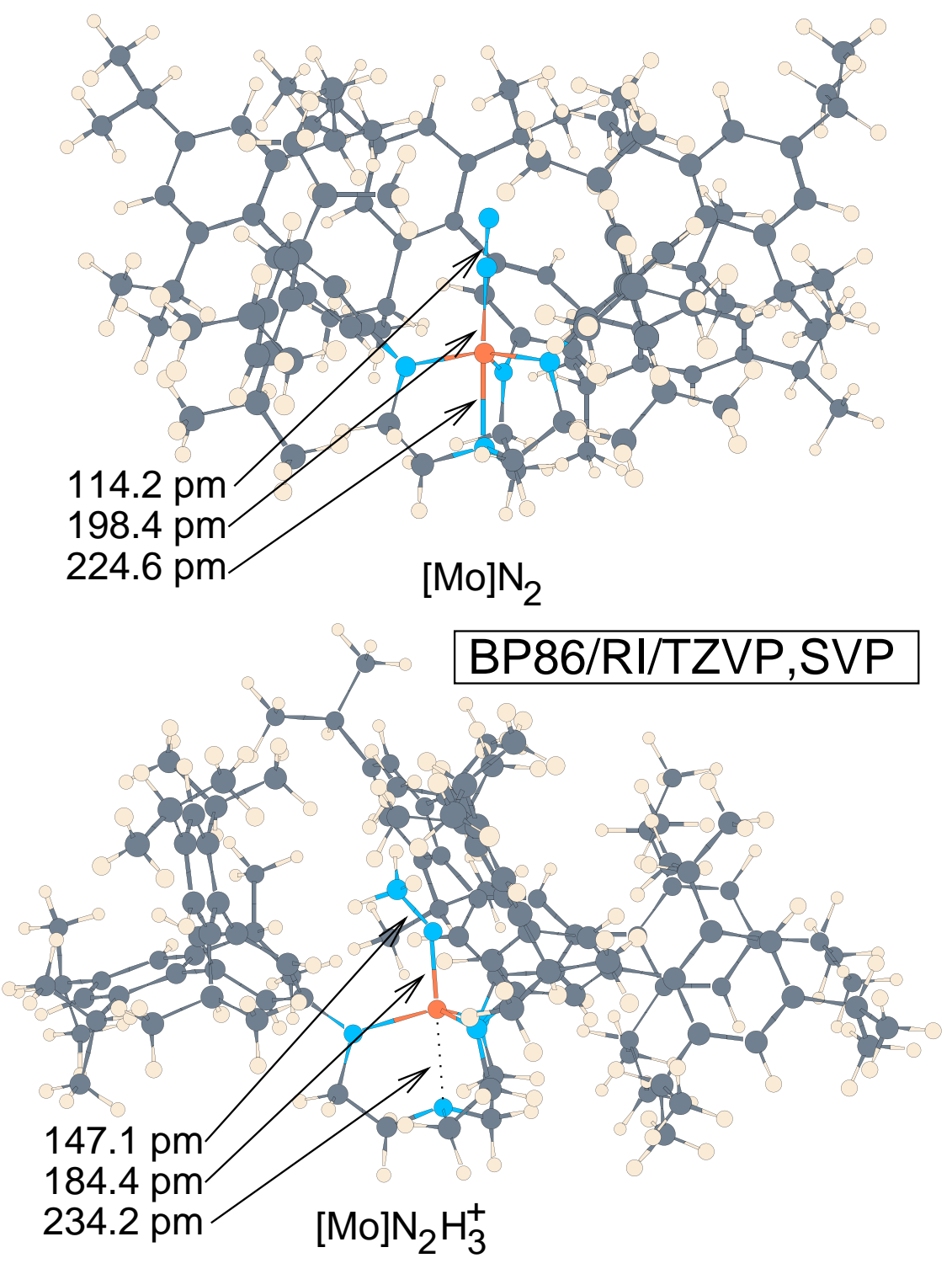


Table 1: $\mathrm{N} \equiv \mathrm{N}$ bond lengths in $\AA$ for the $[\mathrm{Mo}] \mathrm{N}_{2}^{ \pm, 0}$ complexes. The activation of the $\mathrm{N} \equiv \mathrm{N}$ bond increases with increasing negative charge.

\begin{tabular}{lc}
\hline \hline complex & $d_{\mathrm{N} \equiv \mathrm{N}}$ \\
\hline$[\mathrm{Mo}] \mathrm{N}_{2}^{+}$ & 1.131 \\
{$[\mathrm{Mo}] \mathrm{N}_{2}^{0}$} & 1.142 \\
{$[\mathrm{Mo}] \mathrm{N}_{2}^{-}$} & 1.160 \\
\hline \hline
\end{tabular}

We provide information on the molecular picture of the most important steps. These step are labeled a to $\mathbf{f}$ in Fig. 1.

Ammonia abstraction and dinitrogen addition step: The first step a comprises the ligand exchange at the end of the cycle, i.e., the dissociation of $\mathrm{NH}_{3}$ and the addition of $\mathrm{N}_{2}$. Fig. 1 in the communication depicts all elementary reaction steps, which may become important for the $\mathrm{NH}_{3} / \mathrm{N}_{2}$ exchange step a.

On the basis of the reaction energies of Fig. 1 in the main text we identify two energetically favorable routes for the ligand exchange step a. Especially in the presence of a strong reductant, the following elementary steps are likely to take place (path $\mathbf{1}$ ):

$$
[\mathrm{Mo}]\left(\mathrm{NH}_{3}\right)^{+} \stackrel{+e^{-}}{\longrightarrow}[\mathrm{Mo}]\left(\mathrm{NH}_{3}\right) \stackrel{+e^{-}}{\longrightarrow}[\mathrm{Mo}]\left(\mathrm{NH}_{3}\right)^{-} \underset{-\mathrm{NH}_{3}}{\longrightarrow}[\mathrm{Mo}]^{-} \stackrel{+\mathrm{N}_{2}}{\longrightarrow}[\mathrm{Mo}]\left(\mathrm{N}_{2}\right)^{-}
$$

If, however, reduction of the neutral ammine complex cannot be achieved, an alternative route (eventual at higher tenperatures) might be the following path $\mathbf{2}$ :

$$
[\mathrm{Mo}]\left(\mathrm{NH}_{3}\right)^{+} \stackrel{+e^{-}}{\longrightarrow}[\mathrm{Mo}]\left(\mathrm{NH}_{3}\right) \underset{-\mathrm{NH}_{3}}{\longrightarrow}[\mathrm{Mo}] \stackrel{+\mathrm{N}_{2}}{\longrightarrow}[\mathrm{Mo}]\left(\mathrm{N}_{2}\right)
$$

Both steps are consistent with experimental findings that different routes for the catalytic cycle are possible [16].

The open question whether a substitution of $\mathrm{NH}_{3}$ by $\mathrm{N}_{2}$ is favored over the alternative dissociation of $\mathrm{NH}_{3}$ and subsequent addition of $\mathrm{N}_{2}$ may be studied by investigation of the 
structure of the metal fragment [Mo] (Fig. 3). In principle, four reactions channels are possible, but only three are viable since a third side entrance channel appears to be always blocked for sterical reasons (compare Fig. 3). See the main text for further interpretation.

Figure 3: Optimized structure of the neutral metal fragment $[\mathrm{Mo}]$ and possible entrance channels for reactants. Out of three possible side entrance channels, one is blocked for sterical reasons. The diameter of the channel entrances is illustrated by the $\mathrm{C}-\mathrm{C}$ distances given in the figure (in pm).

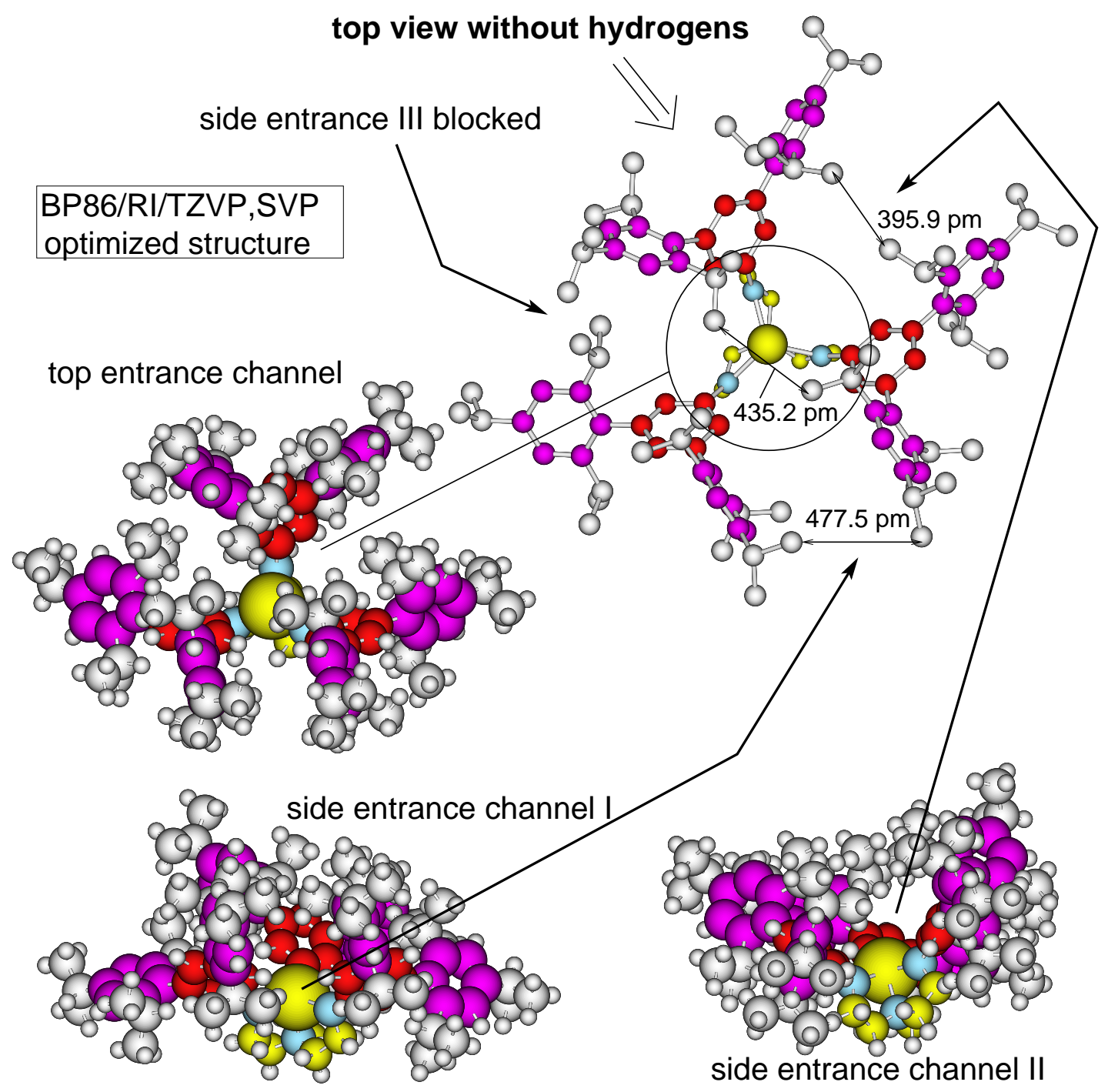

The initial protonation-reduction step: The transfer of the first proton and electron onto the 
coordinated $\mathrm{N}_{2}$ ligand is the crucial step in any dinitrogen activation scheme. See the main text for results and discussion.

The $N-N$ bond breaking step: With respect to the important $\mathrm{N}-\mathrm{N}$ bond breaking step $\mathbf{d}$, which one would consider a crucial step in dinitrogen activation, we note that $\mathrm{NH}_{3}$ immediately dissociates from the metal fragment once the cationic complex $[\mathrm{Mo}] \mathrm{NNH}_{3}^{+}$is reduced. The cationic complex is depicted in Fig. 2; see main text for further discussion. We would like to note that Studt and Tuczek [13] attribute $-303.9 \mathrm{~kJ} / \mathrm{mol}$ to the $\mathrm{N}-\mathrm{N}$ bond breaking reaction, which stems from the fact that these authors compare to a definite electron donor. If a different reductant was used in the calculations, this amount of energy would be different. The reaction energy given by Studt and Tuczek for the N-N bond breaking step almost solely reflects the energy difference required for reduction of the isolated cationic species when compared with the energy required for oxidation of the isolated reductant. One must not get the wrong impression that $\mathrm{N}-\mathrm{N}$ bond breaking yields $-303.9 \mathrm{~kJ} / \mathrm{mol}$. Once the complex is reduced, ammonia dissociates immediately.

The subsequent protonation-reduction steps in the Schrock cycle are calculated to be the more energetically favorable the later they occur in Schrock's cycle (Fig. 2). It is easier to transfer a proton and an electron onto $[\mathrm{Mo}] \mathrm{NH}$ than onto $[\mathrm{Mo}] \mathrm{N}$ or even onto $[\mathrm{Mo}] \mathrm{NNH}$. However, for reaction step $\mathbf{c}$ of Fig. 1 also path $\mathbf{C}$ (Fig. 2 of the main text), which utilizes protonation of an amide nitrogen, might represent a viable route for facilitating activation of $[\mathrm{Mo}] \mathrm{NNH}$. 
Table 2: Protonation and reduction energetics for steps $\mathbf{c}$, e, and $\mathbf{f}$ in $\mathrm{kJ} / \mathrm{mol}$. The total reaction energy $\Delta E_{\text {total }}$ is decomposed into two steps, which may be electron transfer first $\left(\Delta E_{\mathrm{B} .1 \mathrm{e}}\right)$ and proton transfer afterwards $\left(\Delta E_{\mathrm{B} .2 \mathrm{H}}\right)$ - or vice versa, i.e. $\Delta E_{\mathrm{A} .1 \mathrm{H}}$ and $\Delta E_{\mathrm{A} .2 \mathrm{e}}$.

\begin{tabular}{lcrrrrr}
\hline \hline step & reaction & $\Delta E_{\text {total }}$ & $\Delta E_{\mathrm{A} .1 \mathrm{H}}$ & $\Delta E_{\mathrm{A} .2 \mathrm{e}}$ & $\Delta E_{\mathrm{B} .1 \mathrm{e}}$ & $\Delta E_{\mathrm{B} .2 \mathrm{H}}$ \\
\hline $\mathbf{c}$ & {$[\mathrm{Mo}] \mathrm{NNH}+\mathrm{e}^{-}+\mathrm{H}^{+} \rightarrow[\mathrm{Mo}] \mathrm{NNH}_{2}$} & -1460.4 & -32.4 & -1428.0 & -1082.7 & -377.7 \\
$\mathbf{e}$ & {$[\mathrm{Mo}] \mathrm{N}+\mathrm{e}^{-}+\mathrm{H}^{+} \rightarrow[\mathrm{Mo}] \mathrm{NH}$} & -1475.6 & -51.0 & -1424.6 & -1085.2 & -390.3 \\
$\mathbf{f}$ & {$[\mathrm{Mo}] \mathrm{NH}+\mathrm{e}^{-}+\mathrm{H}^{+} \rightarrow[\mathrm{Mo}] \mathrm{NH}_{2}$} & -1604.7 & -79.8 & -1524.9 & -1107.4 & -497.3 \\
\hline \hline
\end{tabular}

\section{Comparison to very recent studies on model systems by Cao et al. and by Studt and Tuczek}

In addition to the comparison given in the last section for the $\mathrm{N}-\mathrm{N}$ bond breaking step as calculated in this work and compared with the results by Studt and Tuczek [13] we shall have a closer look on the possibility to explain dinitrogen reduction with simplified models of the full Schrock complex.

For comparatively small variations in the full chelate ligands, remarkable consequences for the catalytic process were observed by Schrock and collaborators: relatively subtle steric and electronic variations of the $\left[\operatorname{TerN}_{3} N^{3-}\right.$ ligand system produce profound changes in the efficacy of the catalytic reduction of dinitrogen to ammonia [17] and the catalytic reaction clearly is extremely finely balanced [16].

The most simple model of Schrock's complex is the one, where all HIPT substituents of the triamidoamine ligand were substituted by hydrogen atoms. This model was used in the recent study by Studt and Tuczek [13]. We carried out an extensive comparison [12] of three model complexes and the Schrock complex with HMT as the substituent at the triamidoamine complex, which was also studied experimentally by Schrock and collaborators. 
In this comparison [12], we noticed significant electronic as well as steric effects of the fullligand complex when compared to the simplified models. Even the model by Cao et al. [18] appears to be not large enough to reliably represent all reaction steps of Schrock's cycle. For the HIPT ligand we found the following typical deviations (in $\mathrm{kJ} / \mathrm{mol}$ ) to the small models investigated by the other authors (note that we cannot give reference values for the reduction reactions studied by Studt and Tuczek since their data were given with respect to a specific choice of the reductant):

\begin{tabular}{lrrr}
\hline \hline reaction & this work & Cao et al. $[18]$ & Studt \& Tuczek [13] \\
\hline$[\mathrm{Mo}] \mathrm{NH}_{3} \rightarrow[\mathrm{Mo}]+\mathrm{NH}_{3}$ & +116.1 & +77.2 & +36.8 \\
{$[\mathrm{Mo}] \mathrm{NH}_{3}^{+} \rightarrow[\mathrm{Mo}] \mathrm{NH}_{3}$} & -466.0 & -443.8 & \\
{$[\mathrm{Mo}]+\mathrm{N}_{2} \rightarrow[\mathrm{Mo}] \mathrm{N}_{2}$} & -156.7 & -67.5 & -59.4 \\
{$[\mathrm{Mo}] \mathrm{NNH}^{+} \rightarrow[\mathrm{Mo}] \mathrm{NNH}$} & -559.0 & -463.1 & \\
\hline \hline
\end{tabular}

Other intermediates show deviations of similar size. From this table it is evident that both simplified model complex show significant electronic differences from the full ligand system, which is crucial in view of the experimental observation that comparatively small variations in the ligand sphere produce profound changes in the activity of the complex (see above).

We would like to emphasize that the simplified models are also hardly able to provide information on the kinetics of the elementary reactions since the simplified models would provide sufficient space for the elementary reactions to be all of the type of a substitution instead of the addition/dissociation type. The complete picture of the kinetics will become only evident in constrained molecular dynamics calculations on the full complexes, which are currently carried out in our laboratory.

Studt and Tuczek [13] chose a special energy reference level. This was the energy required for electron abstraction from the reductant used in experiment (the protonation reactions were treated accordingly). Therefore, all reaction energies given by these authors can only be understood with respect to these reagents. If a different reductant would be used, the whole energetics of Studt and Tuczek would be different. Thus, we shall not compare the 
energies directly to a chosen reference reductant. We proceed in a different fashion and prefer to give the intrinsic reaction energies as obtained for the isolated complexes although their absolute values may become very large. However, the relative energies are comparable and are not affected by a somehwat artificial choice of the energy reference, which would also not consider the true (differential) microsolvation of the different charged complexes and which is likely to blur error sources inherent and unavoidable in DFT methods.

It is interesting to note that we also observed for some of the smallest model complexes, in which all HIPT substituents were replaced by hydrogen atoms, an unchemical pyramidalization of two out of three amide nitrogen atoms in optimizations with the B3LYP functional and Ahlrichs' TZVP basis set on all atoms. This is no technical artefact but was not observed by Studt and Tuczek [13], who employed a smaller double-zeta basis set for the structure optimizations and a Los Alamos ECP (instead of the ECP by the Stuttgart group employed in this work). As an example, the resulting optimized structure of the ammine complex is shown here:

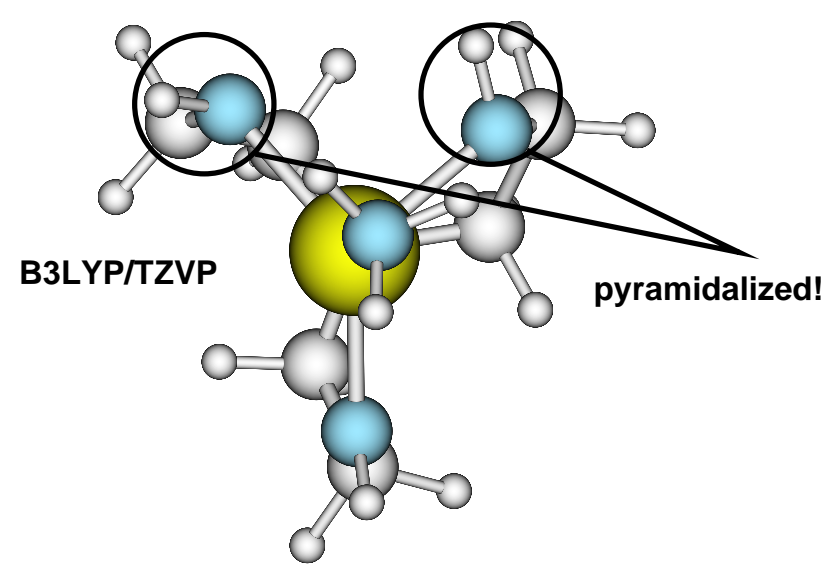

In any case, computational results need to be consistent; We found no pyramidalization in all BP86 optimizations and attribute the effect to the B3LYP functional. Note that the B3LYP implementation in TURBOmole deviates slightly from the one in GaUssian with respect to the choice of the VWN functional. Since DFT is no systematically improvable method there exists no reason to believe that one should fully trust B3LYP data. On the contrary, if problems show up - like in this case - they are a caveat. Therefore, we prefer to discuss the large models, which are much less affected by deviations of B3LYP from BP86. 
We will present additional details and comparisons on the different models in a future full paper.

\section{Acknowledgements}

Financial support by the collaborative research centers SFB 436 ("Metallvermittelte Reaktionen nach dem Vorbild der Natur", Jena) and SFB 624 ("Template", Bonn) as well as by the Fonds der Chemischen Industrie (FCI) are gratefully acknowledged. M.R. is grateful to the FCI for granting a Dozentenstipendium.

\section{References}

[1] Ahlrichs, R.; Bär, M.; Häser, M.; Horn, H.; Kölmel, C. Chem. Phys. Lett. 1989, 162, 165-169.

[2] Becke, A. D. Phys. Rev. A 1988, 38, 3098-3100.

[3] Perdew, J. P. Phys. Rev. B 1986, 33, 8822-8824.

[4] Andrae, D.; Häußermann, U.; Dolg, M.; Stoll, H.; Preuß, H. Theor. Chim. Acta 1990, $77,123-141$.

[5] Eichkorn, K.; Treutler, O.; Öhm, H.; Häser, M.; Ahlrichs, R. Chem. Phys. Lett. 1995, 240, 283-290.

[6] Eichkorn, K.; Weigend, F.; Treutler, O.; Ahlrichs, R. Theor. Chem. Acc. 1997, 97, 119-124.

[7] Schäfer, A.; Huber, C.; Ahlrichs, R. J. Chem. Phys. 1994, 100, 5829-5835.

[8] Schäfer, A.; Horn, H.; Ahlrichs, R. J. Chem. Phys. 1992, 97, 2571-2577.

[9] Reiher, M.; Hess, B. A. Chem. Eur. J. 2002, 8, 5332-5339. 
[10] Becke, A. D. J. Chem. Phys. 1993, 98, 5648-5652.

[11] Stephens, P. J.; Devlin, F. J.; Chabalowski, C. F.; Frisch, M. J. J. Phys. Chem. 1994, 98, 11623-11627.

[12] Guennic, B. L.; Kirchner, B.; Reiher, M. Chem. Eur. J. 2005, accepted for publication.

[13] Studt, F.; Tuczek, F. Angew. Chem. Int. Ed. 2005, 44, 5639-5642.

[14] Yandulov, D. V.; Schrock, R. R. Science 2003, 301, 76-78.

[15] Schrock, R. R. Chem. Comm. 2003, 2389-2391.

[16] Yandulov, D. V.; Schrock, R. R. Inorg. Chem. 2005, 44, 1103-1117.

[17] Ritleng, V.; Yandulov, D. V.; Weare, W. W.; Schrock, R. R.; Hock, A. S.; Davis, W. M. J. Am. Chem. Soc. 2004, 126, 6150-6163.

[18] Cao, Z.; Zhou, Z.; Wan, H.; Zhang, Q. Int. J. Quantum Chem. 2005, 103, 344-353. 